\title{
RESEARCH
}

Open Access

\section{Association between number of dissected lymph nodes and survival in stage IA non- small cell lung cancer: a propensity score matching analysis}

Lei-Lei $\mathrm{Wu}^{1+}$, Jia-Jian Lai ${ }^{2+}$, Xuan Liu' ${ }^{1}$, Yang-Yu Huang ${ }^{1}$, Peng Lin' ${ }^{1}$, Hao Long ${ }^{1}$, Lan-Jun Zhang ${ }^{1}$ and Guo-Wei Ma ${ }^{1,3^{*}}$ (D)

\begin{abstract}
Background: For patients with stage IA non-small cell lung cancer (NSCLC) with tumor size $\leq 2 \mathrm{~cm}$, the prognostic significance of the number of removed lymph nodes (NLNs) through different surgical methods remains unclear. To determine the association of NLNs with cancer-specific survival (CSS) and overall survival (OS) in patients with stage IA NSCLC with tumor size $\leq 2 \mathrm{~cm}$ who underwent different lung surgeries.

Methods: We retrospectively enrolled 7293 patients from the Surveillance, Epidemiology and End Results database. Median NLNs was used to classify the patients into two groups: group A with NLNs $\leq 5$ and group B with NLNs >

5. Propensity score matching (PSM) was performed to decrease selection bias. Kaplan-Meier analysis and Cox regression analysis were performed to identify the association between NLNs and survival outcomes.

Results: Group B had better survival than group A in the unmatched cohort and matched cohort (all $P<0.05$ ). Multivariable analyses revealed that the NLNs significantly affected CSS and OS of eligible cases in the unmatched cohort and matched cohort. Additionally, we found that the NLNs was a protective prognostic predictor of OS for patients who underwent wedge resection, segmental resection, or lobectomy.

Conclusion: The NLNs was a protective prognostic factor in NSCLC patients with tumor size $\leq 2 \mathrm{~cm}$. We demonstrated that patients with $>5$ NLNs in the cohort of wedge resection, segmental resection, or lobectomy exhibited a significantly better OS.
\end{abstract}

Keywords: Non-small cell lung cancer, Lymph nodes, Prognosis, Surgery, Small tumor size

\footnotetext{
* Correspondence: magw@sysucc.org.cn

${ }^{\dagger}$ Lei-Lei Wu and Jia-Jian Lai contributed equally to this work.

'Sun Yat-sen University Cancer Center, State Key Laboratory of Oncology in

South China, Collaborative Innovation Center for Cancer Medicine,

Guangzhou 510060, P. R. China

${ }^{3}$ The Department of Thoracic Surgery, Sun Yat-sen University Cancer Center,

651 Dongfengdong Road, Guangzhou 510060, P. R. China

Full list of author information is available at the end of the article
}

C C The Author(s). 2020 Open Access This article is licensed under a Creative Commons Attribution 4.0 International License, which permits use, sharing, adaptation, distribution and reproduction in any medium or format, as long as you give appropriate credit to the original author(s) and the source, provide a link to the Creative Commons licence, and indicate if changes were made. The images or other third party material in this article are included in the article's Creative Commons licence, unless indicated otherwise in a credit line to the material. If material is not included in the article's Creative Commons licence and your intended use is not permitted by statutory regulation or exceeds the permitted use, you will need to obtain permission directly from the copyright holder. To view a copy of this licence, visit http://creativecommons.org/licenses/by/4.0/ The Creative Commons Public Domain Dedication waiver (http://creativecommons.org/publicdomain/zero/1.0/) applies to the data made available in this article, unless otherwise stated in a credit line to the data. 


\section{Introduction}

Lung cancer is one of the most aggressive malignancies worldwide. In 2019, lung cancer accounted for $13 \%$ of all estimated new cancer cases and onequarter of all estimated cancer deaths in adults [1]. Patients with stage IA (according to $8^{\text {th }}$ American Joint Committee on Cancer [AJCC] Staging Manual) non-small-cell lung cancer (NSCLC) may undergo different surgical treatments, such as wedge resection, segmental resection, lobectomy, or pneumonectomy; however, their 5-year overall survival rate remains around 73-90\% [2]. Lobectomy along with mediastinal lymph nodes (LNs) resection has been considered the standard surgical treatment for early-stage NSCLC for more than 2 decades [3]. LNs' dissection is widely used to determine the accurate pathologic staging of NSCLC and to provide guidance regarding the prognosis and additional treatments. Multiple studies have indicated that LN resection conferred benefit in terms of the survival outcomes of patients with stage T1-4N0M0 NSCLC [4-8]. Furthermore, it seems that the dissection of more number of LNs may result in a clearer TNM classification and improve the survival outcomes of patients $[9,10]$.

Whereas with the popularization of computed tomography (CT)-based screening and application of some CT features, the predictive ability to distinguish benign and malignant lesions of small pulmonary nodules has significantly improved [11-13]. Patients with clinical stage I NSCLC commonly undergo lung cancer screening by CT, which helps detect the pulmonary nodules. Recently, the results of JCOG0804 demonstrated that for patients who were found with a lesion with a diameter $\leq 2 \mathrm{~cm}$ and a solid component $\leq 25 \%$, the 5 -year disease-free survival rate of those patients with sub-lobectomy was 99.7\% [14]. Therefore, surgeons and patients might consider sub-lobar resection, including wedge resection, and segmental resection as a preferred treatment approach to protect more healthy tissues in the lung. However, with increased sub-lobar resection, the decision to include LN dissection remains controversial. In addition, few studies have investigated the relationship between $\mathrm{LN}$ resection and the survival outcomes of patients with clinical stage IA (8th AJCC) NSCLC with tumor size $\leq 2$

\section{SEER database}

(1) Pathologically diagnosed as lung cancer (LC);

(2) Complete follow-up;

(3) Virtual survival status and clear survival time;

(4) First malignant and one primary;

(5) Diagnosis between 2004 and 2015

$(\mathrm{N}=\mathbf{3 3 6 , 8 1 0})$

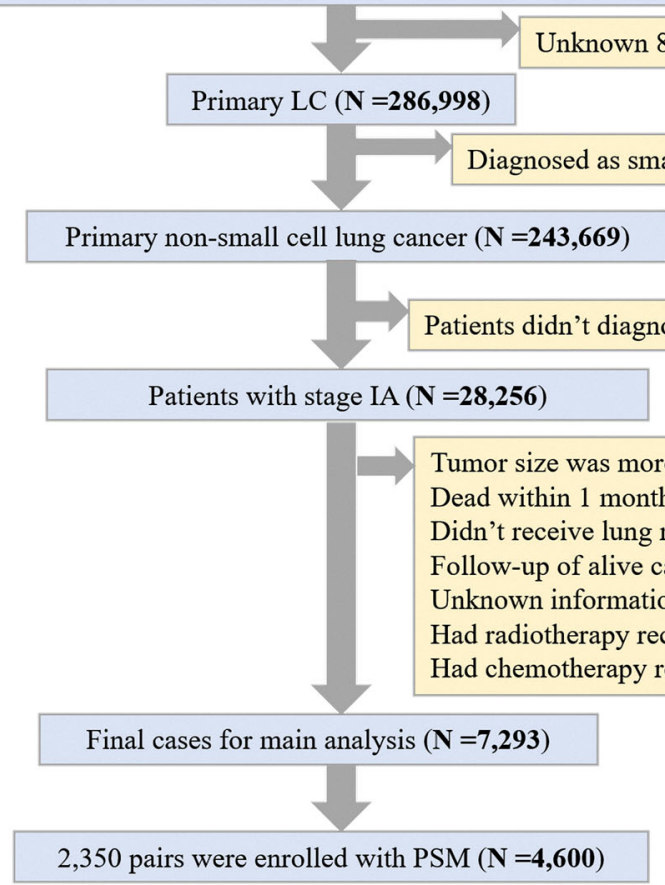

Fig. 1 The flow diagram of this study 
Table 1 Baseline characteristics of patients with stage IA NSCLC $\leq 2 \mathrm{~cm}$ in size stratified by NLNs without and with PSM

\begin{tabular}{|c|c|c|c|c|c|c|}
\hline \multirow[b]{2}{*}{ Groups } & \multicolumn{3}{|l|}{ Without PSM } & \multicolumn{3}{|l|}{ With PSM } \\
\hline & NLNs $\leq 5$ & NLNs $>5$ & $p$ value & NLNs $\leq 5$ & NLNs $>5$ & $p$ value \\
\hline Total & 3850 & 3443 & & 2350 & 2350 & \\
\hline Sex (\%) & & & $0.437^{*}$ & & & $0.423^{*}$ \\
\hline Male & 1588 (41.2\%) & $1452(42.2 \%)$ & & 968 (41.2\%) & 940 (40.0\%) & \\
\hline Female & 2262 (58.8\%) & 1991 (57.8\%) & & $1382(58.8 \%)$ & $1410(60.0 \%)$ & \\
\hline Age (\%) & & & $<0.001^{*}$ & & & $0.906^{*}$ \\
\hline$\leq 65$ & $1468(38.1 \%)$ & $1517(44.1 \%)$ & & $990(42.1 \%)$ & 985 (41.9\%) & \\
\hline$>65$ & 2382 (61.9\%) & 1926 (55.9\%) & & $1360(57.9 \%)$ & $1365(58.1 \%)$ & \\
\hline TNM stage (\%) & & & $0.004^{*}$ & & & $1^{*}$ \\
\hline$|A|$ & 703 (18.3\%) & 541 (15.7\%) & & 349 (14.9\%) & $350(14.9)$ & \\
\hline $\mathrm{A} 2$ & 3147 (81.7\%) & 2902 (84.3\%) & & 2001 (85.1\%) & $2000(85.1 \%)$ & \\
\hline Grade (\%) & & & $<0.001^{*}$ & & & $0.707^{*}$ \\
\hline 1 & $841(21.8 \%)$ & $774(22.5 \%)$ & & 525 (22.3\%) & $530(22.6 \%)$ & \\
\hline$\|$ & 1622 (42.1\%) & $1569(45.6 \%)$ & & 1045 (44.5\%) & 999 (42.5\%) & \\
\hline III & 992 (25.8\%) & 847 (24.6\%) & & $578(24.6 \%)$ & 609 (25.9\%) & \\
\hline IV & $55(1.4 \%)$ & $37(1.1 \%)$ & & $32(1.4 \%)$ & $32(1.4 \%)$ & \\
\hline Unknown & $340(8.8 \%)$ & $216(6.3 \%)$ & & $170(7.2 \%)$ & $180(7.7 \%)$ & \\
\hline Tumor location (\%) & & & $<0.001^{* *}$ & & & $1^{* *}$ \\
\hline Upper lobe & 2258 (58.6\%) & $2289(66.5 \%)$ & & $1388(59.1 \%)$ & 1395 (59.4\%) & \\
\hline Middle lobe` & $311(8.1 \%)$ & $148(4.3 \%)$ & & $148(6.3 \%)$ & $146(6.2 \%)$ & \\
\hline Lower lobe & $1216(31.6 \%)$ & 965 (28.0\%) & & 783 (33.3\%) & 777 (33.1\%) & \\
\hline Main bronchus & $5(0.1 \%)$ & $4(0.1 \%)$ & & $1(0.0 \%)$ & $1(0.0 \%)$ & \\
\hline Overlapping & $16(0.4 \%)$ & $12(0.3 \%)$ & & $10(0.4 \%)$ & $10(0.4 \%)$ & \\
\hline Lung NOS & $44(1.1 \%)$ & $25(0.7 \%)$ & & $20(0.9 \%)$ & $21(0.9 \%)$ & \\
\hline Tumor size (mean (SD) (mm)) & $14.72(4.03)$ & $15.05(3.86)$ & $<0.001^{* * *}$ & $15.12(3.88)$ & $15.08(3.81)$ & $0.690^{* * *}$ \\
\hline Race (\%) & & & $0.059^{* * *}$ & & & $0.972^{* *}$ \\
\hline American Indian & $15(0.4 \%)$ & $14(0.4 \%)$ & & $10(0.4 \%)$ & $12(0.5 \%)$ & \\
\hline Asian & $194(5.0 \%)$ & $203(5.9 \%)$ & & $141(6.0 \%)$ & $148(6.3 \%)$ & \\
\hline Black & $324(8.4 \%)$ & $239(6.9 \%)$ & & $197(8.4 \%)$ & $196(8.3 \%)$ & \\
\hline White & 3308 (85.9\%) & $2983(86.6 \%)$ & & $3(0.1 \%)$ & $4(0.2 \%)$ & \\
\hline Unknown & $9(0.2 \%)$ & $4(0.1 \%)$ & & 1999 (85.1\%) & $1990(84.7 \%)$ & \\
\hline Surgical methods (\%) & & & $<0.001^{* *}$ & & & $1^{* *}$ \\
\hline Wedge resection & $1417(36.8 \%)$ & $230(6.7 \%)$ & & $230(9.8 \%)$ & $230(9.8 \%)$ & \\
\hline Segmental resection & $284(7.4 \%)$ & $80(2.3 \%)$ & & 79 (3.4\%) & 79 (3.4\%) & \\
\hline Lobectomy & $2126(55.2 \%)$ & $3102(90.1 \%)$ & & $2030(86.4 \%)$ & $2030(86.4 \%)$ & \\
\hline Pneumonectomy & $17(0.4 \%)$ & $28(0.8 \%)$ & & $11(0.5 \%)$ & $11(0.5 \%)$ & \\
\hline Unknown & $6(0.2 \%)$ & $3(0.1 \%)$ & & $0(0.0 \%)$ & $0(0.0 \%)$ & \\
\hline Histological types (\%) & & & $0.157^{* *}$ & & & $0.866^{* *}$ \\
\hline Adeno & $2503(65.0 \%)$ & $2297(66.7 \%)$ & & $1592(67.7 \%)$ & $1565(66.6 \%)$ & \\
\hline SCC & $861(22.4 \%)$ & $745(21.6 \%)$ & & $494(21.0 \%)$ & $510(21.7 \%)$ & \\
\hline LCC & $117(3.0 \%)$ & $74(2.1 \%)$ & & $56(2.4 \%)$ & $60(2.6 \%)$ & \\
\hline PSC & $3(0.1 \%)$ & $2(0.1 \%)$ & & $1(0.0 \%)$ & $0(0.0 \%)$ & \\
\hline Other & $222(5.8 \%)$ & $210(6.1 \%)$ & & $134(5.7 \%)$ & $136(5.8 \%)$ & \\
\hline Unknown & 144 (3.7\%) & 115 (3.3\%) & & 73 (3.1\%) & 79 (3.4\%) & \\
\hline
\end{tabular}

NSCLC non-small cell lung cancer, NLNs the number of removed lymph nodes, PSM propensity score matching, Lung NOS uncertain location on lung, Adeno adenocarcinoma, SCC squamous cell carcinoma, LCC large cell carcinoma, PSC pulmonary sarcomatoid carcinoma, Other other histological types

"Chi-squared test

"Fisher's exact test

*** Student's $t$ test 
$\mathrm{cm}$ who underwent different types of lung surgery (wedge resection, segmental resection, lobectomy, pneumonectomy) [7].

Therefore, we aimed to investigate whether resection of more LNs resulted in better survival outcomes among patients with clinical stage IA NSCLC with tumor size $\leq 2 \mathrm{~cm}$ and to determine the effects of the number of removed lymph nodes (NLNs) on conferring survival benefit to patients who underwent wedge resection, segmental resection, lobectomy, or pneumonectomy.

\section{Materials and methods}

\section{Patients}

This study was a retrospective study and approved by the Clinical Research Ethics Committee of Sun Yat-sen University Cancer Center (IRB number: B2019-116-01), and the need for informed consent of patients was waived. Between 2004 and 2015, 7293 patients with stage IA NSCLC and tumor size $\leq 2 \mathrm{~cm}$ from the Surveillance, Epidemiology, and End Results (SEER) database were retrospectively included in this study. The clinical TNM classifications were based on the 8th edition AJCC classification criteria. The inclusion criteria were as follows: (1) pathologically diagnosed as lung cancer (LC), (2) complete follow-up, (3) virtual survival status and clear survival time, (4) first malignancy and one primary, (5) diagnosis between 2004 and 2015, (6) primary non-small cell lung cancer, and (7) patients with clinical stage IA. The exclusion criteria were as follows: (1) Unknown 8th AJCC TNM stage, (2) diagnosed as small cell lung cancer, (3) stage other than IA, (4) tumor size more than $20 \mathrm{~mm}$, (5) dead within 1 month, (6) did not receive lung resection, (7) follow-up of alive cases was within 60 months, (8) unknown information on lymph node resection, (9) had radiotherapy records, and (10) had chemotherapy records.

\section{Data collection}

SEER is a population-based cancer registry that is made up of 18 geographically distinct tumor registries and covers $26 \%$ of the United States population. The data that supported the findings of this study are available in SEER Stat software (version 8.3.8), reference number:
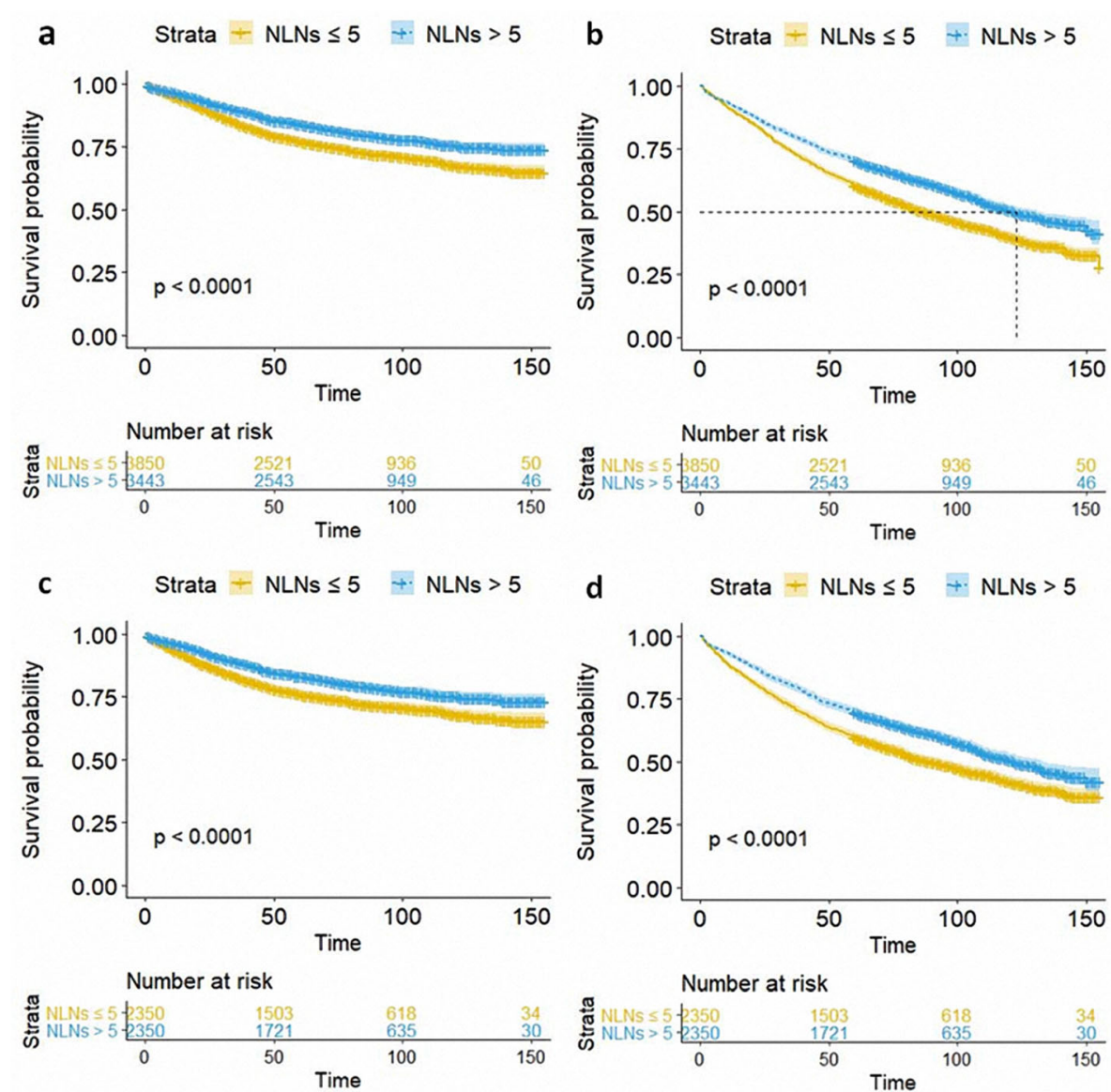

Fig. 2 Kaplan-Meier curves showing the effect of NLNs on CSS (a) and OS (b) of unmatched patients with stage IA $\leq 2-\mathrm{cm}$ NSCLC. Kaplan-Meier curves showing the effect of NLNs on CSS (c) and OS (d) of matched patients with stage IA $\leq 2-\mathrm{cm}$ NSCLC 
Table 2 The association between NLNs and CSS together with OS in univariate and multivariate analyses without PSM

\begin{tabular}{|c|c|c|c|c|c|c|c|}
\hline \multirow{3}{*}{ Variable } & \multirow{3}{*}{ Number } & \multicolumn{3}{|l|}{ CSS } & \multicolumn{3}{|l|}{ OS } \\
\hline & & \multirow{2}{*}{$\begin{array}{l}\text { Univariate } \\
\text { analysis } \\
p \text { value }\end{array}$} & \multicolumn{2}{|l|}{ Multivariate analysis } & \multirow{2}{*}{$\begin{array}{l}\text { Univariate } \\
\text { analysis } \\
p \text { value }\end{array}$} & \multicolumn{2}{|l|}{ Multivariate analysis } \\
\hline & & & HR (95\%Cls) & $p$ value & & HR (95\%Cls) & $p$ value \\
\hline \multicolumn{8}{|l|}{ NLNs } \\
\hline$\leq 5$ & 3850 & & 1 (reference) & & & 1 (reference) & \\
\hline$>5$ & 3443 & $<0.001$ & $0.791(0.710-0.882)$ & $<0.001$ & $<0.001$ & $0.821(0.763-0.884)$ & $<0.001$ \\
\hline \multicolumn{8}{|l|}{ Sex } \\
\hline Male & 3040 & & 1 (reference) & & & 1 (reference) & \\
\hline Female & 4253 & $<0.001$ & $0.757(0.686-0.835)$ & $<0.001$ & $<0.001$ & $0.723(0.676-0.773)$ & $<0.001$ \\
\hline \multicolumn{8}{|l|}{ Age } \\
\hline$\leq 65$ & 2985 & & 1 (reference) & & & 1 (reference) & \\
\hline$>65$ & 4308 & $<0.001$ & $1.548(1.393-1.720)$ & $<0.001$ & $<0.001$ & $1.946(1.806-2.096)$ & $<0.001$ \\
\hline \multicolumn{8}{|l|}{ TNM stage } \\
\hline $\mid \mathrm{A} 1$ & 1244 & & 1 (Reference) & & & 1 (Reference) & \\
\hline $\mathrm{A} 2$ & 6049 & 0.003 & $1.023(0.843-1.243)$ & 0.815 & $<0.001$ & $1.038(0.911-1.182)$ & 0.578 \\
\hline \multicolumn{8}{|l|}{ Grade } \\
\hline I & 1615 & & 1 (reference) & & & 1 (reference) & \\
\hline$\|$ & 3191 & $<0.001$ & 2.109 (1.794-2.479) & $<0.001$ & $<0.001$ & $1.631(1.471-1.807)$ & $<0.001$ \\
\hline III & 1839 & $<0.001$ & $2.810(2.364-3.341)$ & $<0.001$ & $<0.001$ & $2.004(1.792-2.242)$ & $<0.001$ \\
\hline IV & 92 & $<0.001$ & $1.476(0.911-2.392)$ & 0.113 & $<0.001$ & $1.303(0.944-1.797)$ & 0.107 \\
\hline Unknown & 556 & $<0.001$ & $1.785(1.414-2.253)$ & $<0.001$ & $<0.001$ & $1.407(1.207-1.640)$ & $<0.001$ \\
\hline \multicolumn{8}{|l|}{ Tumor location (\%) } \\
\hline Upper lobe & 4547 & & & & & 1 (Reference) & \\
\hline Middle lobe & 459 & 0.597 & & & 0.017 & $0.895(0.773-1.036)$ & 0.138 \\
\hline Lower lobe & 2181 & 0.794 & & & 0.712 & $1.038(0.964-1.119)$ & 0.320 \\
\hline Main bronchus & 9 & 0.427 & & & 0.351 & $0.800(0.257-2.485)$ & 0.699 \\
\hline Overlapping & 28 & 0.821 & & & 0.431 & $1.429(0.859-2.378)$ & 0.169 \\
\hline Lung NOS & 69 & 0.176 & & & 0.148 & $1.114(0.811-1.530)$ & 0.506 \\
\hline Tumor size (mm) & - & $<0.001$ & $1.022(1.004-1.041)$ & 0.015 & $<0.001$ & $1.018(1.005-1.030)$ & 0.005 \\
\hline \multicolumn{8}{|l|}{ Race } \\
\hline American Indian & 29 & & & & & 1 (Reference) & \\
\hline Asian & 397 & 0.725 & & & 0.160 & $0.613(0.346-1.083)$ & 0.092 \\
\hline Black & 563 & 0.410 & & & 0.742 & $0.962(0.551-1.679)$ & 0.890 \\
\hline White & 6291 & 0.548 & & & 0.747 & $0.920(0.533-1.587)$ & 0.764 \\
\hline Unknown & 13 & 0.981 & & & 0.049 & $0.150(0.020-1.150)$ & 0.068 \\
\hline \multicolumn{8}{|l|}{ Surgical methods } \\
\hline Wedge resection & 1647 & & 1 (reference) & & & 1 (reference) & \\
\hline Segmental resection & 364 & 0.397 & $0.944(0.757-1.178)$ & 0.610 & 0.009 & $0.841(0.721-0.981)$ & 0.027 \\
\hline Lobectomy & 5228 & $<0.001$ & $0.719(0.637-0.812)$ & $<0.001$ & $<0.001$ & $0.696(0.641-0.756)$ & $<0.001$ \\
\hline Pneumonectomy & 45 & 0.033 & $1.957(1.183-3.238)$ & 0.009 & 0.030 & $1.623(1.137-2.315)$ & 0.008 \\
\hline Unknown & 6 & 0.426 & $0.430(0.060-3.061)$ & 0.399 & 0.284 & $0.567(0.182-1.763)$ & 0.327 \\
\hline \multicolumn{8}{|l|}{ Histological types } \\
\hline Adeno & 4800 & & 1 (reference) & & & 1 (reference) & \\
\hline SCC & 1606 & $<0.001$ & $1.046(0.926-1.182)$ & 0.470 & $<0.001$ & $1.376(1.271-1.490)$ & $<0.001$ \\
\hline LCC & 191 & $<0.001$ & $1.666(1.276-2.175)$ & $<0.001$ & $<0.001$ & $1.533(1.257-1.869)$ & $<0.001$ \\
\hline
\end{tabular}


Table 2 The association between NLNs and CSS together with OS in univariate and multivariate analyses without PSM (Continued)

\begin{tabular}{|c|c|c|c|c|c|c|c|}
\hline \multirow{3}{*}{ Variable } & \multirow{3}{*}{ Number } & \multicolumn{3}{|l|}{ CSS } & \multicolumn{3}{|l|}{ OS } \\
\hline & & \multirow{2}{*}{$\begin{array}{l}\text { Univariate } \\
\text { analysis } \\
p \text { value }\end{array}$} & \multicolumn{2}{|c|}{ Multivariate analysis } & \multirow{2}{*}{$\begin{array}{l}\text { Univariate } \\
\text { analysis } \\
p \text { value }\end{array}$} & \multicolumn{2}{|l|}{ Multivariate analysis } \\
\hline & & & HR (95\%Cls) & $p$ value & & HR (95\%Cls) & $p$ value \\
\hline PSC & 5 & 0.012 & $2.516(0.808-7.832)$ & 0.111 & 0.036 & $1.691(0.633-4.517)$ & 0.294 \\
\hline Other & 432 & 0.011 & $1.241(1.014-1.518)$ & 0.036 & 0.020 & $1.140(0.984-1.321)$ & 0.080 \\
\hline Unknown & 259 & 0.008 & $0.971(0.755-1.247)$ & 0.815 & $<0.001$ & $1.135(0.961-1.339)$ & 0.136 \\
\hline
\end{tabular}

NSCLC non-small cell lung cancer, NLNs the number of removed lymph nodes, PSM propensity score matching, HR hazard ratio, Cls confident intervals, Lung NOS uncertain location on lung, Adeno adenocarcinoma, SCC squamous cell carcinoma, LCC large cell carcinoma, PSC pulmonary sarcomatoid carcinoma, Other other histological types

SEER 18 Regs Custom Data, Nov Sub (1975-2016 varying).

\section{Statistical analyses}

The baseline characteristics between the two groups were evaluated using the chi-squared test, Fisher's exact test, and Student's $t$ test. Both Kaplan-Meier analysis and the log-rank test were used to investigate the role of NLNs in cancer-specific survival (CSS) and overall survival (OS). Univariable and multivariable Cox regression analyses were performed to test the significant variables associated with CSS and OS. All statistical tests were two-sided, and probability values ( $p$ value $)<0.05$ were considered statistically significant. Hazard ratio (HR) alongside 95\% confidence intervals (CIs) was used to present the relative risk of the factors. Standard deviation (SD) was used to evaluate the stability of data in this cohort. The cutoff point of NLNs was determined using the median. Besides, to improve the test level and minimize the selection bias of the study, a 1:1 patient paired propensity score matching (PSM) analysis was performed. Age at diagnosis (age), sex, race/ethnicity, tumor size, TNM stage, grade, histological types, and surgical approaches were considered as covariates in the PSM model. With PSM, 2350 pairs were generated from 7293 eligible patients. All data in this study were analyzed using R (3.6.1) (https://www.r-project.org/).

\section{Results}

\section{Patient characteristics}

A total of 7293 eligible patients were enrolled in this study. The flow chart of this study is shown in Fig. 1. The median size of the tumor was $1.5 \mathrm{~cm}$ (range 0.1-2.0 $\mathrm{cm}$ ). Similarly, the mean tumor size was $1.5 \mathrm{~cm}$ (SD 0.4 $\mathrm{cm}$ ). Meanwhile, the median NLNs was 5 (range 0-78) and the mean NLNs was 6.72 (SD 6.88). The patients were divided into two groups according to the median NLNs. A total of 3850 patients had $\leq 5$ LNs dissected, whereas 3443 patients had $>5$ LNs dissected. Table 1 shows the baseline characteristics of patients stratified by NLNs $(\leq 5$ and $>5)$ before and after PSM. Before PSM, a significant difference between the two groups was seen in terms of age $(P<0.001)$, stage $(P=0.004)$, tumor location $(P<0.001)$, tumor size $(P<0.001)$, and surgical methods $(P<0.001)$. With PSM, 2350 pairs of patients were eligible for analysis and further stratified by the NLNs ( $\leq 5$ and $>5$ ). Because of PSM, both groups were well balanced as all the variables were not significantly different between groups.

\section{Effect of NLNs on survival outcomes}

Kaplan-Meier analysis and log-rank tests were performed to investigate the effect of NLNs on CSS and OS in the eligible patients without and with PSM. The analysis revealed a common trend in the unmatched and matched cohorts; patients with $>5$ NLNs (group B) showed significantly better CSS and OS than those patients with $\leq 5$ NLNs (group A) (all $p$ values $<0.001$ ) (Fig. 2). Precisely, in the unmatched cohort, the 1-, 3-, and 5-year CSS of group A (NLNs $\leq 5)$ were $94.8 \%$, $84.4 \%$, and $77.3 \%$, respectively, while the corresponding values of group B (NLNs > 5) were $96.6 \%, 89.5 \%$, and $84.1 \%$. Similarly, the 1-, 3-, and 5-year OS of group A (NLNs $\leq 5$ ) were $90.2 \%, 73.4 \%$, and $60.5 \%$, respectively, while the corresponding values for group B (NLNs > 5) were $92.3 \%, 80.0 \%$, and $70.4 \%$. Likewise, after PSM, 1-, $3-$, and 5-year CSS of group A (NLNs $\leq 5)$ were $93.3 \%$, $83.0 \%$, and $76.1 \%$, respectively, while the corresponding values for group B (NLNs > 5) were 96.3\%, 88.7\%, and 83.3\%. As for OS, 1-, 3-, and 5-year OS of group A (NLNs $\leq 5$ ) were $87.4 \%, 71.5 \%$, and $59.7 \%$, respectively, while the corresponding values for group B (NLNs > $)$ were $92.3 \%, 79.7 \%$, and $69.7 \%$.

To further validate the impact of NLNs on OS and CSS, univariable and multivariable analyses were conducted in the unmatched and matched cohorts. Without PSM, the univariable analysis revealed that NLNs, sex, age at diagnosis, TNM stage, grade, tumor size, surgical methods, and histological types were associated with CSS while NLNs, sex, age at diagnosis, TNM stage, grade, tumor location, tumor size, race/ethnicity, surgical methods, and histological types were associated with OS of the patients (Table 2). In addition, the multivariable analysis also revealed that NLNs, sex, age at diagnosis, grade, tumor size, 
Table 3 The association between NLNs and CSS together with OS in univariate and multivariate analyses with PSM

\begin{tabular}{|c|c|c|c|c|c|c|c|}
\hline \multirow{3}{*}{ Variable } & \multirow{3}{*}{ Number } & \multicolumn{3}{|l|}{ CSS } & \multicolumn{3}{|l|}{ os } \\
\hline & & \multirow{2}{*}{$\begin{array}{l}\text { Univariate } \\
\text { analysis } \\
p \text { value }\end{array}$} & \multicolumn{2}{|l|}{ Multivariate analysis } & \multirow{2}{*}{$\begin{array}{l}\text { Univariate } \\
\text { analysis } \\
p \text { value }\end{array}$} & \multicolumn{2}{|c|}{ Multivariate analysis } \\
\hline & & & HR (95\%Cls) & $p$ value & & HR (95\%Cls) & $p$ value \\
\hline \multicolumn{8}{|l|}{ NLNs } \\
\hline$\leq 5$ & 2350 & & 1 (reference) & & & 1 (reference) & \\
\hline$>5$ & 2350 & $<0.001$ & $0.631(0.557-0.714)$ & $<0.001$ & $<0.001$ & $0.650(0.597-0.708)$ & $<0.001$ \\
\hline \multicolumn{8}{|l|}{ Sex } \\
\hline Male & 1908 & & 1 (reference) & & & 1 (reference) & \\
\hline Female & 2790 & $<0.001$ & $0.631(0.557-0.714)$ & $<0.001$ & $<0.001$ & $0.714(0.657-0.777)$ & $<0.001$ \\
\hline \multicolumn{8}{|l|}{ Age } \\
\hline$\leq 65$ & 1975 & & 1 (reference) & & & 1 (reference) & \\
\hline$>65$ & 2725 & $<0.001$ & $1.410(1.244-1.599)$ & $<0.001$ & $<0.001$ & $1.829(1.671-2.002)$ & $<0.001$ \\
\hline \multicolumn{8}{|l|}{ TNM stage } \\
\hline$|\mathrm{A}|$ & 699 & & 1 (reference) & & & 1 (reference) & \\
\hline IA2 & 4001 & 0.005 & $1.153(0.900-1.478)$ & 0.261 & 0.003 & $1.117(0.944-1.322)$ & 0.197 \\
\hline \multicolumn{8}{|l|}{ Grade } \\
\hline 1 & 1055 & & 1 (reference) & & & 1 (reference) & \\
\hline$\|$ & 2044 & $<0.001$ & $2.094(1.724-2.543)$ & $<0.001$ & $<0.001$ & $1.642(1.446-1.864)$ & $<0.001$ \\
\hline III & 1187 & $<0.001$ & $2.762(2.242-3.402)$ & $<0.001$ & $<0.001$ & $2.055(1.791-2.360)$ & $<0.001$ \\
\hline IV & 64 & 0.007 & $1.574(0.901-2.748)$ & 0.111 & 0.007 & $1.248(0.843-1.847)$ & 0.268 \\
\hline Unknown & 350 & 0.005 & $1.643(1.222-2.210)$ & 0.001 & 0.037 & $1.277(1.045-1.560)$ & 0.017 \\
\hline
\end{tabular}

Tumor location (\%)

Upper lobe
Middle lobe
Lower lobe
Main bronchus
Overlapping
Lung NOS

2783

$294 \quad 0.640$

$1560 \quad 0.627$

20.982

20

0.891

0.079

$<0.001$

$1.019(0.997-1.042)$

0.094

Race

American Indian 22

$\begin{array}{ll}\text { Asian } & 289 \\ \text { Black } & 393\end{array}$

White

Unknown

3989

$$
7
$$

Surgical methods

Wedge resection

Segmental resection

Lobectomy

Pneumonectomy

Unknown

Histological types

$\begin{array}{lll}\text { Adeno } & 3157 & \\ \text { SCC } & 1004 & <0.001 \\ \text { LCC } & 116 & <0.001\end{array}$

\subsection{0}

0.455

0.667

0.978

460

158

4060

22

0

0.025

$<0.001$

0.533

NA

$<0.001$
1 (reference)

$0.546(0.392-0.761)$

$0.339(0.283-0.405)$

$0.581(0.256-1.318)$

NA

$<0.001$

$<0.001$

0.194

NA

1 (reference)

$1.064(0.915-1.237)$

0.424

$1.640(1.163-2.314 \quad 0.005$

0.158

0.443

0.973

0.977

0.230

$<0.001$

1.014 (0.999-1.030)

0.066

0.225

0.865

0.924

0.967

$$
0.96
$$

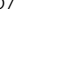


Table 3 The association between NLNs and CSS together with OS in univariate and multivariate analyses with PSM (Continued)

\begin{tabular}{|c|c|c|c|c|c|c|c|}
\hline \multirow{3}{*}{ Variable } & \multirow{3}{*}{ Number } & \multicolumn{3}{|l|}{ CSS } & \multicolumn{3}{|l|}{ OS } \\
\hline & & \multirow{2}{*}{$\begin{array}{l}\text { Univariate } \\
\text { analysis } \\
p \text { value }\end{array}$} & \multicolumn{2}{|c|}{ Multivariate analysis } & \multirow{2}{*}{$\begin{array}{l}\text { Univariate } \\
\text { analysis } \\
p \text { value }\end{array}$} & \multicolumn{2}{|l|}{ Multivariate analysis } \\
\hline & & & HR (95\%Cls) & $p$ value & & HR (95\%Cls) & $p$ value \\
\hline PSC & 1 & 0.981 & 0.000 (0.000-Inf) & 0.981 & 0.981 & 0.000 (0.000-Inf) & 0.972 \\
\hline Other & 270 & 0.140 & $1.140(0.883-1.472)$ & 0.314 & 0.082 & $1.117(0.929-1.342)$ & 0.240 \\
\hline Unknown & 152 & 0.575 & $0.867(0.612-1.228)$ & 0.422 & 0.008 & $1.086(0.867-1.361)$ & 0.472 \\
\hline
\end{tabular}

NSCLC non-small cell lung cancer, NLNs the number of removed lymph nodes, PSM propensity score matching, HR hazard ratio, Cls confident intervals, Lung NOS uncertain location on lung, Adeno adenocarcinoma, SCC squamous cell carcinoma, LCC large cell carcinoma, PSC pulmonary sarcomatoid carcinoma, Other other histological types, Inf infinity

surgical methods, and histological types independently predicted both CSS and OS (Table 2). After PSM, the univariable analysis confirmed that NLNs, sex, age at diagnosis, TNM stage, grade, tumor size, surgical methods, and histological types were statistically significant predictors for CSS and OS. In addition, the multivariable Cox regression analysis also revealed that NLNs, sex, age at diagnosis, grade, surgical methods, and histological types were independent predictors for CSS and OS (Table 3). In summary, univariable and multivariable analyses uniformly indicated that the NLNs were a significant and independent prognostic factor in the unmatched and matched patients.

Besides, the patients who underwent lobectomy or wedge resection and with more than $5 \mathrm{LNs}$ resected had a significantly better CSS $(P<0.001, P=0.0095$, respectively), while no significant impact on conferring better CSS was observed for segmental resection, and pneumonectomy, although the $p$ values of segmental resection were near 0.05 (Fig. 3). Meanwhile, the number of dissected LNs
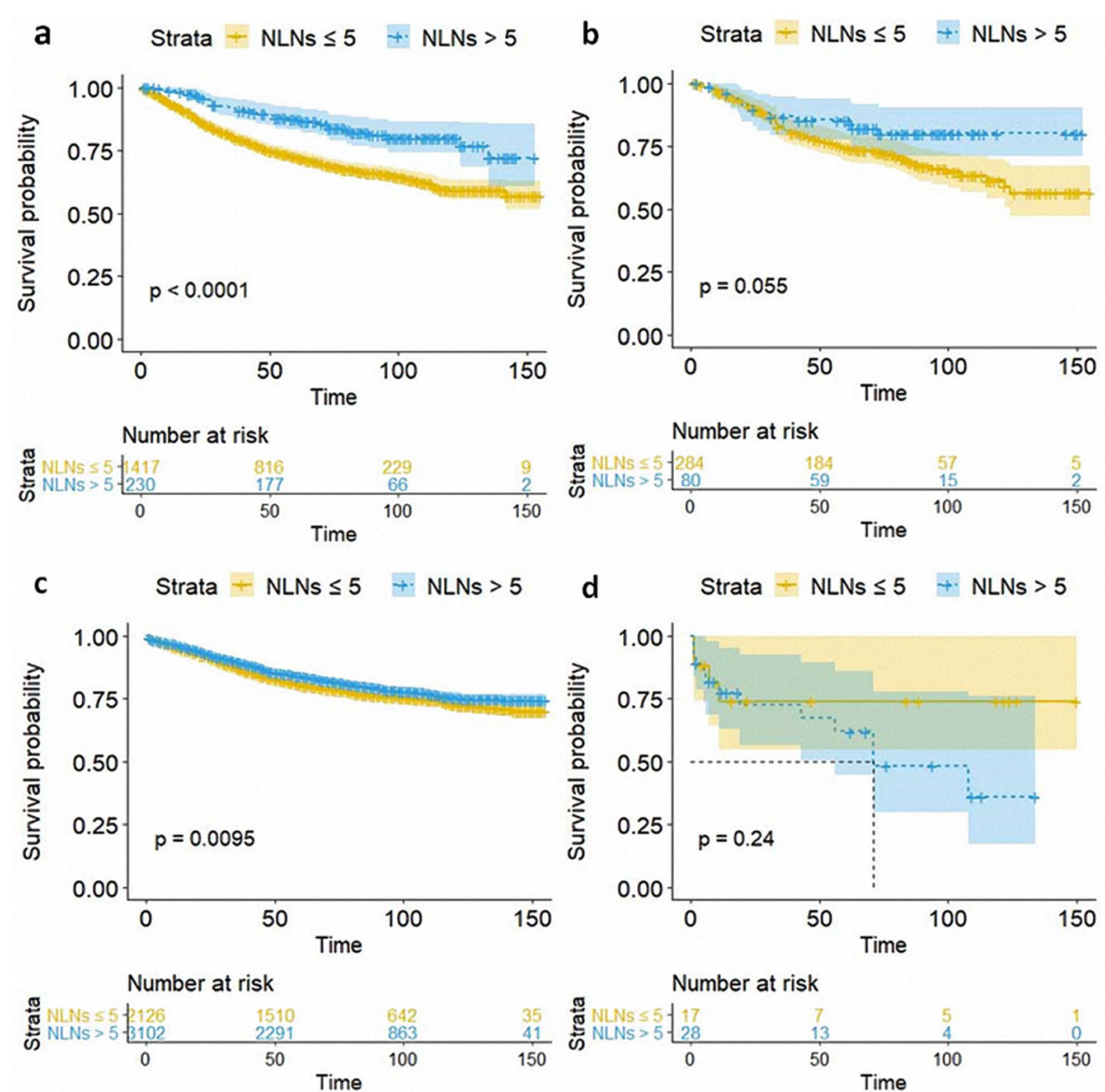

Fig. 3 Kaplan-Meier curves showing CSS for patients with NLNs $\leq 5$ and $>5$ who underwent wedge resection (a), segmental resection (b), lobectomy (c), and pneumonectomy (d) 
contributed to the better OS of patients who underwent wedge resection, segmental resection, and lobectomy, $(P<$ $0.001, P=0.028, P=0.0051$, respectively) (Fig. 4).

\section{Subgroup analysis of survival outcomes}

Furthermore, a subgroup analysis was conducted to investigate the effect of listed factors in Table 1 on CSS and OS of eligible patients (without PSM). The effects of the rest of the variables on CSS and OS were illustrated in Figs. 5 and 6, respectively.

\section{Discussion}

This study examined the relationship between NLNs and the survival outcomes of patients with stage IA NSCLC $\leq 2 \mathrm{~cm}$ in size who underwent different types of lung surgeries. Kaplan-Meier analysis and log-rank test demonstrated that patients with more than 5 LNs dissected showed significantly better CSS and OS in the unmatched and matched patients, which indicates that dissection of more LNs might result in better survival. In addition, both univariable and multivariable analyses revealed that NLNs served as a protective prognostic predictor for CSS and OS in the unmatched and matched patients. Further, according to our subgroup study, patients who underwent wedge resection, segmental resection, or lobectomy rather than pneumonectomy, together with resection of more than $5 \mathrm{LNs}$, had statistically better survival outcomes. To sum up, patients with stage IA NSCLC $\leq 2 \mathrm{~cm}$ in size who undergo wedge resection, segmental resection, or lobectomy may have better survival outcomes after undergoing incremental NLNs.

To date, the relationship between NLNs and survival outcome for patients with stage IA NSCLC $\leq 2 \mathrm{~cm}$ in size remains controversial. Dissection of more LNs may result in a clearer TNM classification, a higher possibility to discover, and eradicate occult metastasis, and therefore a better survival outcome $[9,10]$. Further, Burdett et al. noted that an increase in NLNs can make the pTNM stage more precise that it is beneficial to decide the strategy of adjuvant therapy [15]. Several retrospective studies based on the SEER database have confirmed the relationship between NLNs and survival
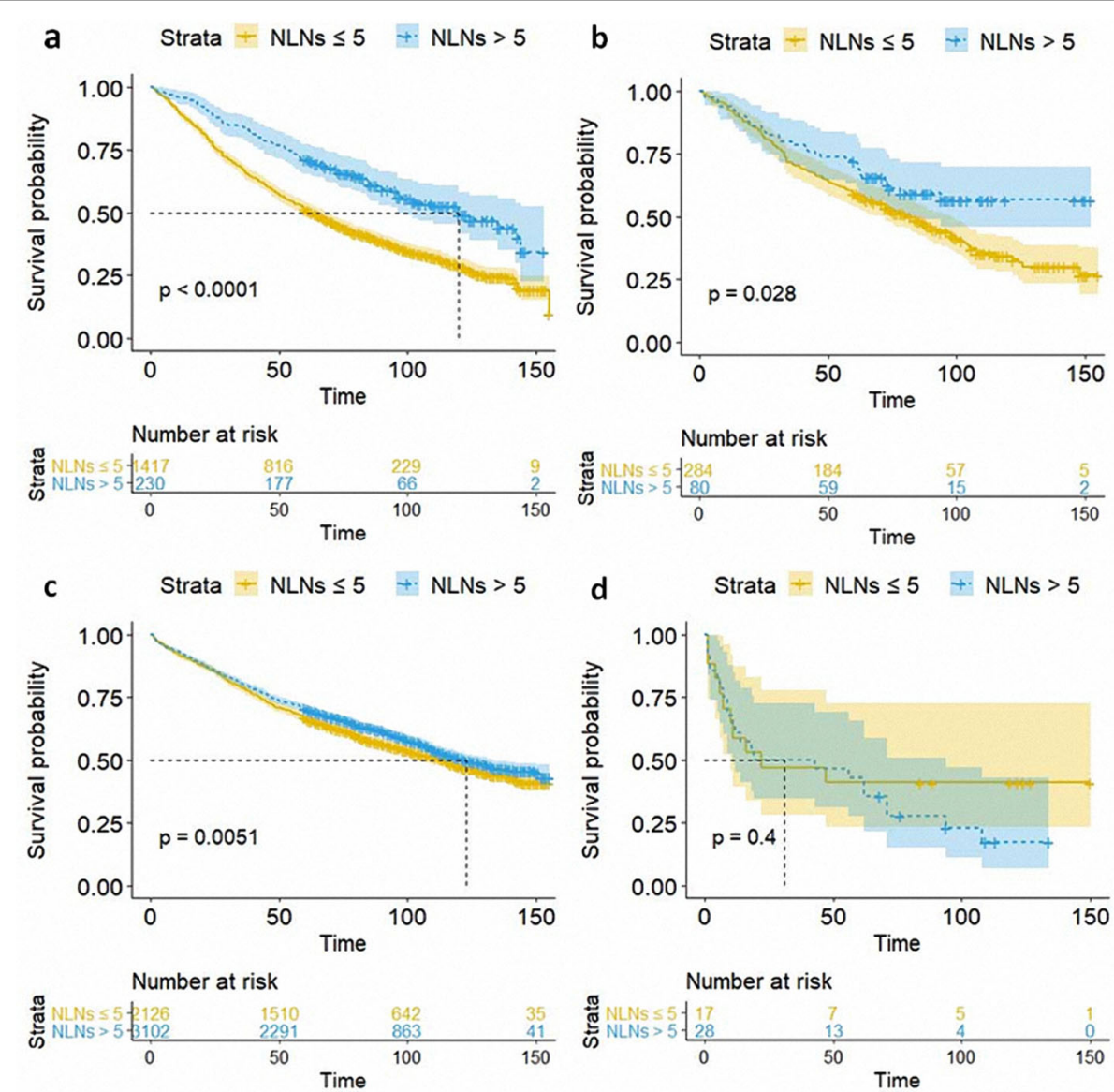

Fig. 4 Kaplan-Meier curves showing OS for patients with NLNs $\leq 5$ and $>5$ who underwent wedge resection (a), segmental resection (b), lobectomy (c), and pneumonectomy (d) 


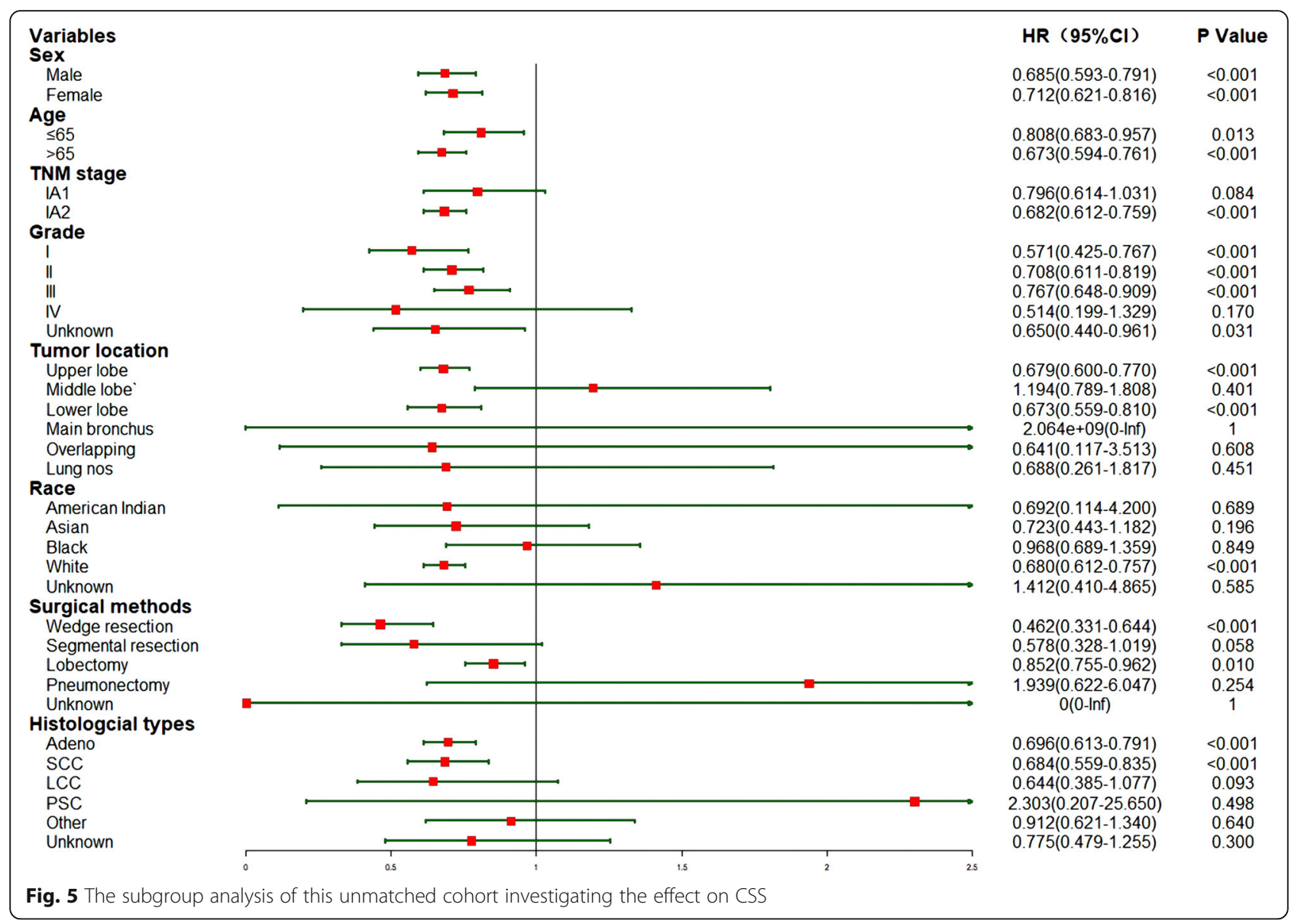

outcomes of patients with stage NO NSCLC and have proposed optimal NLNs for survival outcomes [4, 6-8]. Furthermore, Osarogiagbon et al. suggested that the resection of 11 to 15 LNs might be associated with better survival [6]. Similarly, Becker et al. observed a consistently increasing survival benefit for patients with 16 to 18 LNs removed [8]. Additionally, several single-center studies also highlighted the relationship. However, a study conducted by Saji et al. determined the optimal minimum NLNs as 8 for patients with stage I NSCLC [16]. Moreover, Wen et al. demonstrated that patients with stage T2N0M0 NSCLC should have at least $12 \mathrm{LNs}$ resected during the surgery [5]. In addition, the minimal NLNs for patients with NO NSCLC was not clear. Likewise, the NCCN guidelines indicate that $\mathrm{N} 1$ and $\mathrm{N} 2$ nodes should be dissected, and mapping should be performed; however, it does not specify the minimum NLNs [17]. Conversely, the European Society of Thoracic Surgeons guidelines proposes that at least six LNs from the hilar and mediastinal stations should be removed for accurate nodal staging [10].

Unfortunately, only a few studies have focused on whether NLNs is associated with the survival outcomes of patients with stage IA NSCLC $2 \mathrm{~cm}$ or less. Ding et al. demonstrated that 4 to $16 \mathrm{LNs}$ should be examined for patients with NSCLC $<2 \mathrm{~cm}$ undergoing wedge resection, and these NLNs could provide a survival advantage to those patients. However, among patients who received segmentectomy, LN resection did not improve survival outcomes [7]. In Ding's study, there were some stage IB patients, as they did not exclude the patients with pleura invasion. Wolf et al. showed that lobectomy led to superior survival compared to sub-lobar resection in patients with NO NSCLC $\leq 2 \mathrm{~cm}$; however, the survival outcome was not different from that in patients with LN resection performed together with lobectomy [18]. In contrast, our study revealed that LN resection conferred independent survival benefit to patients with NSCLC $\leq$ $2 \mathrm{~cm}$, and NLNs contributed to survival benefit for patients who received wedge resection, segmental resection, or lobectomy, but not for patients who received pneumonotomy. Several theories can explain this phenomenon. There were only 45 patients who underwent pneumonectomy in comparison to a larger number of patients who received wedge resection, segmental resection, or lobectomy in our study $(n=1647,364,5228$, respectively), and a small sample entails a risk of bias. Notably, the patients who received lobectomy or 


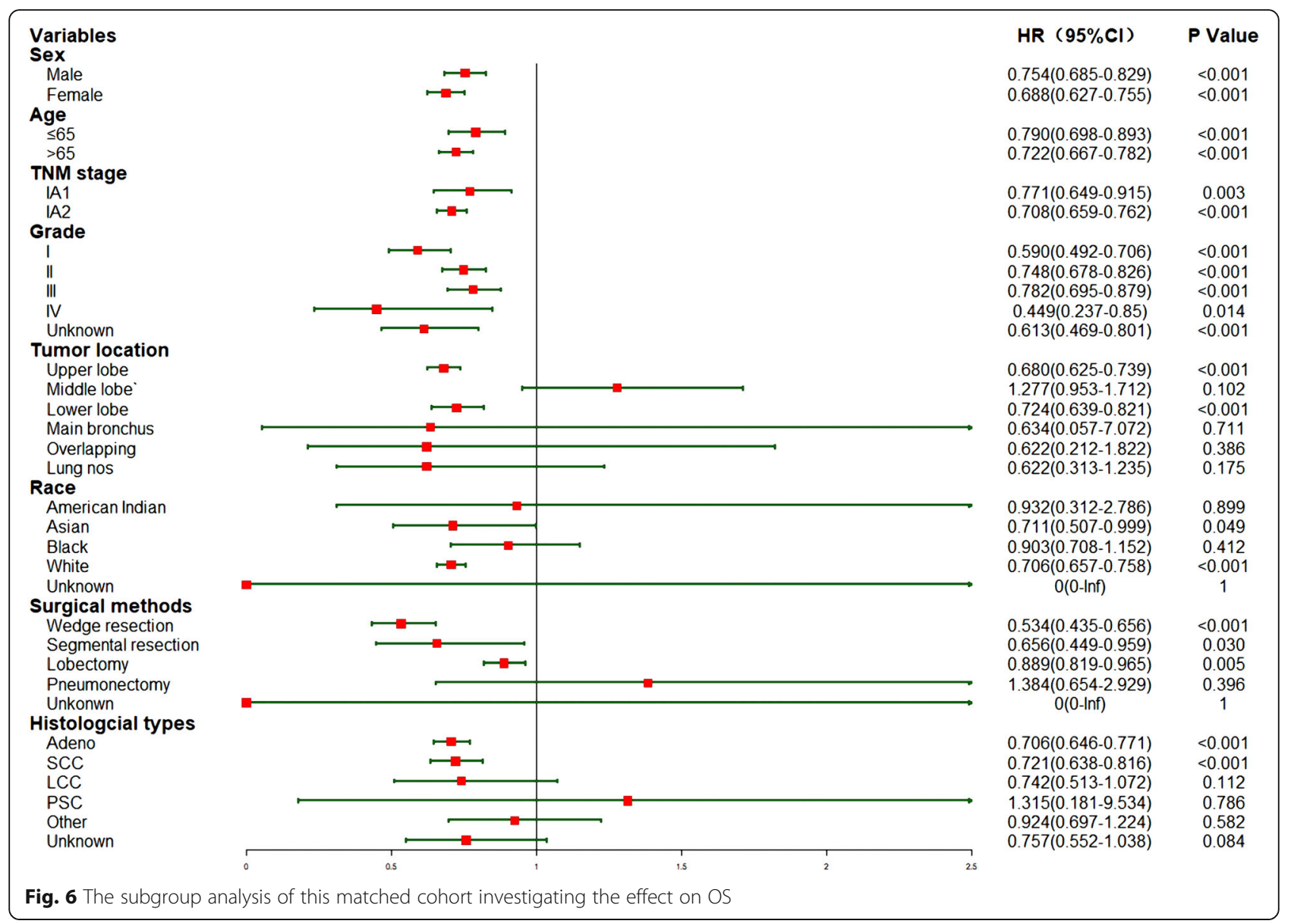

wedge resection and with more than 5 LNs dissected had a significantly better CSS, while there was no effect of dissection of more than 5 LNs with segmental resection, or pneumonectomy on CSS. The smaller sample sizes of patients undergoing segmental resection, or pneumonectomy might be responsible for it. Since $p$ values of segmental resection were both near $0.05(P=$ $0.055)$, and univariable and multivariable studies together with a subgroup study on OS revealed that all the four surgical methods except pneumonectomy together with dissection of more than 5 LNs contributed to better survival outcome, we concluded that patients who underwent wedge resection, segmental resection, or lobectomy had better survival outcome after having incremental NLNs.

There are several limitations to this study. Because of the retrospective nature of the study, the bias in our results was inevitably unremovable. However, the potential selection bias derived from a retrospective study was minimized by performing PSM. Due to the short followup period and a low malignancy rate of stage IA NSCLC tumors $\leq 2 \mathrm{~cm}$, the median survival time of all patients was not identified. The exact location of the dissected LNs was unknown due to the statistical limitations.
Moreover, our findings did not provide an exact optimal NLNs for LN dissection in clinical practice. Despite these limitations, we believe that our study could be used as a reference for the treatment of patients with stage IA NSCLC $\leq 2 \mathrm{~cm}$ in size who undergo wedge resection, segmental resection, or lobectomy.

\section{Conclusions}

In conclusion, NLNs was a strong prognosticator for patients who received wedge resection, segmental resection, or lobectomy rather than pneumonectomy. Our study indicates that patients with stage IA NSCLC $\leq 2$ $\mathrm{cm}$ who undergo wedge resection, segmental resection, or lobectomy should undergo higher NLNs to achieve better OS, but the efficacy of our conclusions should be investigated further by a large-scale, prospective, multicenter study.

\section{Abbreviations}

NSCLC: Non-small cell lung cancer; NLNs: The number of removed lymph nodes; CSS: Cancer-specific survival; OS: Overall survival; SEER: Surveillance, Epidemiology, and End Results database; PSM: Propensity score matching; AJCC: American Joint Committee on Cancer; LNs: Lymph nodes;

CT: Computed tomography; LC: Lung cancer; HR: Hazard ratio;

Cls: Confidence intervals; SD: Standard deviation; Lung NOS: Uncertain

location on lung; Adeno: Adenocarcinoma; SCC: Squamous cell carcinoma; 
LCC: Large cell carcinoma; PSC: Pulmonary sarcomatoid carcinoma; Other: Other histological types; Inf: Infinity

\section{Acknowledgments}

Our sincere thanks to colleagues in the Department of Thoracic Surgery, Sun Yat-sen University Cancer Center. Thanks to our respected pioneer, Professor Tie-Hua Rong, who oriented us to surgical oncology. We thank our patients who provided their information for medical research; they were the best teachers for doctors. We appreciate Editage (https://app.editage.com/) for reviewing and editing our manuscript.

\section{Authors' contributions}

MGW, WLL, and LJ did the conception and design of the work. $L P, L H, Z \sqcup$, and MGW provided the study materials or patients. WLL, LJJ, and HYY did the acquisition of data. MGW, WLL, and LJ analyzed the data. MGW, LP, LH $Z L$, , WLL interpretated the data. WLL and LJ drafted the manuscript. MGW and WLL substantially revised the manuscript. The authors read and approved the final manuscript.

\section{Funding}

This research did not receive any specific grant from funding agencies in the public, commercial, or not-for-profit sectors.

\section{Availability of data and materials}

Please contact author for data requests.

\section{Ethics approval and consent to participate}

The study protocol was approved by the Ethics Committee of Sun Yat-sen University Cancer Center (IRB No. B2019-116-01); the requirement of informed consent was waived

\section{Consent for publication}

Not applicable.

\section{Competing interests}

The authors declare that they have no competing interests.

\section{Author details}

'Sun Yat-sen University Cancer Center, State Key Laboratory of Oncology in South China, Collaborative Innovation Center for Cancer Medicine,

Guangzhou 510060, P. R. China. ${ }^{2}$ Sun Yat-sen University, Guangzhou 510060, P. R. China. ${ }^{3}$ The Department of Thoracic Surgery, Sun Yat-sen University Cancer Center, 651 Dongfengdong Road, Guangzhou 510060, P. R. China.

Received: 4 June 2020 Accepted: 23 November 2020

Published online: 07 December 2020

\section{References}

1. Siegel RL, Miller KD, Jemal A. Cancer statistics, 2019. CA Cancer J Clin. 2019; 69:7-34

2. Rami-Porta R, Asamura H, Travis WD, Rusch W. Lung cancer - major changes in the American Joint Committee on Cancer eighth edition cancer staging manual. CA Cancer J Clin. 2017;67:138-55.

3. Ginsberg RJ, Rubinstein LV. Randomized trial of lobectomy versus limited resection for T1 N0 non-small cell lung cancer. Lung Cancer Study Group. Ann Thorac Surg. 1995;60:615-22 discussion 622-613.

4. Wu L-L, Liu X, Jiang W-M, et al. Stratification of patients with stage IB NSCLC based on the 8th Edition of the American Joint Committee on Cancer (AJCC) Staging Manual. Front Oncol. 2020;10:1-9.

5. Wen YS, Xi KX, Xi KX, et al. The number of resected lymph nodes is associated with the long-term survival outcome in patients with T2 N0 nonsmall cell lung cancer. Cancer Manag Res. 2018;10:6869-77.

6. Osarogiagbon RU, Ogbata O, Yu X. Number of lymph nodes associated with maximal reduction of long-term mortality risk in pathologic node-negative non-small cell lung cancer. Ann Thorac Surg. 2014;97:385-93.

7. Ding $\mathrm{H}$, Wang $\mathrm{H}, \mathrm{Xu} \mathrm{L}$, et al. Survival and resected lymph node number during sublobar resection for NO non-small cell lung cancer $2 \mathrm{~cm}$ or less. Ann Thorac Surg. 2019;107:1647-55.

8. Becker DJ, Levy BP, Gold HT, et al. Influence of extent of lymph node evaluation on survival for pathologically lymph node negative non-small cell lung cancer. Am J Clin Oncol. 2018:41:820-5.
9. Nomori $H$, Mori $T$, Izumi $Y$, et al. Is completion lobectomy merited for unanticipated nodal metastases after radical segmentectomy for cT1 NO M0/pN1-2 non-small cell lung cancer? J Thorac Cardiovasc Surg. 2012; 143:820-4.

10. De Leyn P, Lardinois D, Van Schil PE, et al. ESTS guidelines for preoperative lymph node staging for non-small cell lung cancer. Eur J Cardiothorac Surg. 2007;32:1-8.

11. Yang $W$, Sun $Y$, Fang $W$, et al. High-resolution computed tomography features distinguishing benign and malignant lesions manifesting as persistent solitary subsolid nodules. Clin Lung Cancer. 2018;19:e75-83.

12. Liu Y, Wang H, Li Q, et al. Radiologic features of small pulmonary nodules and lung cancer risk in the national lung screening trial: a nested casecontrol study. Radiology, 2018;286:298-306.

13. Suzuki K, Koike T, Asakawa T, et al. A prospective radiological study of thinsection computed tomography to predict pathological noninvasiveness in peripheral clinical IA lung cancer (Japan Clinical Oncology Group 0201). J Thorac Oncol. 2011;6:751-6.

14. Suzuki K, Watanabe $S$, Wakabayashi $M$ et al. A single-arm study of sublobar resection for ground glass opacity dominant peripheral lung cancer. J Thorac Cardiovasc Surg. 2020: In press.

15. Burdett S, Pignon JP, Tierney J, et al. Adjuvant chemotherapy for resected early-stage non-small cell lung cancer. Cochrane Database Syst Rev. 2015: Cd011430. https://doi.org/10.1002/14651858.CD011430.

16. Saji H, Tsuboi M, Yoshida K, et al. Prognostic impact of number of resected and involved lymph nodes at complete resection on survival in non-small cell lung cancer. J Thorac Oncol. 2011:6:1865-71.

17. National Comprehensive Cancer Network. Non-Small Cell Lung Cancer(Version 7.2019). Availble online at: https://www.nccn.org/ professionals/physician__gls/pdf/nscl.pdf (Accessed 30 Aug 2019).

18. Wolf AS, Richards WG, Jaklitsch MT, et al. Lobectomy versus sublobar resection for small (2 cm or less) non-small cell lung cancers. Ann Thorac Surg. 2011;92:1819-23 discussion 1824-1815

\section{Publisher's Note}

Springer Nature remains neutral with regard to jurisdictional claims in published maps and institutional affiliations.

Ready to submit your research? Choose BMC and benefit from:

- fast, convenient online submission

- thorough peer review by experienced researchers in your field

- rapid publication on acceptance

- support for research data, including large and complex data types

- gold Open Access which fosters wider collaboration and increased citations

- maximum visibility for your research: over $100 \mathrm{M}$ website views per year

At BMC, research is always in progress.

Learn more biomedcentral.com/submission 